\title{
Molecular markers associated with potentially malignant oral lesions (Review)
}

\author{
OANA MIHAELA CONDURACHE HRITCU ${ }^{1,2^{*}}$, ANA EMANUELA BOTEZ ${ }^{1 *}$, DOINITA TEMELIE OLINICI ${ }^{1 *}$, \\ P. ONOFREI ${ }^{1}$, LAURA STOICA ${ }^{1}$, V. B. GRECU ${ }^{1}$, PAULA MIHAELA TOADER ${ }^{2}$, \\ LAURA GHEUCĂ-SOLOVĂSTRU ${ }^{2}$ and ELENA CARMEN COTRUTZ ${ }^{1}$ \\ Departments of ${ }^{1}$ Cell and Molecular Biology, and ${ }^{2}$ Dermatology, \\ 'Gr. T. Popa' University of Medicine and Pharmacy, 700115 Iasi, Romania
}

Received March 26, 2021; Accepted April 26, 2021

DOI: $10.3892 / \mathrm{etm} .2021 .10266$

\begin{abstract}
According to literature data, potentially premalignant oral lesions are the basis of over $85 \%$ of cell carcinomas. Despite multiple advances achieved during the last few decades in the diagnosis and treatment of oral squamous cell carcinomas, there has not been a significant change in the prognosis and 5-year survival rate. The prevention of malignant transformation of these tumors by diagnosis and targeted treatment would be the ideal scenario. These potentially premalignant oral lesions represent an important subject for either the clinical or the research field, due to the higher malignant transformation observed in the last few years at different ages. To date, histopathological examination based on TNM criteria is considered the 'golden standard'. However, this type of examination has its limitation due to staining procedures and photonic microscope examination. Identification of cellular and molecular markers specific to these oral lesions with potentially malignant transformation could lead to early detection, accurate diagnosis, prevention of the development of oral squamous cell carcinoma (OSCC) and facilitate a targeted therapeutic approach. In this review, we focused on a series of molecules that are implicated in the malignant transformation of these lesions and considered potential biomarkers.
\end{abstract}

Correspondence to: Dr Ana Emanuela Botez or Dr Doinita Temelie Olinici, Department of Cell and Molecular Biology, 'Gr. T. Popa' University of Medicine and Pharmacy, 16 Universitatii Street, 700115 Iasi, Romania

E-mail: emma.botez@yahoo.com

E-mail: doinitzaganceanu@yahoo.com

*Contributed equally

Key words: squamous cell carcinoma, potentially malignant oral lesions, molecular markers, molecules associated with apoptosis, biomarkers of angiogenesis, molecules associated with cell adhesion

\section{Contents}

1. Introduction

2. Molecules associated with the phases of the cell cycle and apoptosis

3. Biomarkers of angiogenesis

4. Metalloproteinases

5. Molecules associated with cell adhesion

6. Conclusions

\section{Introduction}

Despite the progress made in the field of oncology in recent years, oral cancer remains a major worldwide health issue. With over 300,000 new cases diagnosed annually, squamous cell carcinoma is one of the most common forms of oral cancer, with a high morbidity and mortality rate, and a 5-year survival rate lower than $<50 \%$ (1). Most squamous cell carcinomas develop from lesions with malignant transformation potential. One of the most common lesion types is leukoplakia, with a malignant transformation rate of $<2 \%$ in one year. This rate of malignant transformation varies between 1.1 and $17.5 \%$ among oral lesions with epithelial dysplasia (2).

Identifying lesions with the potential for malignant transformation and adequate management seems to be the key in the secondary prevention of squamous cell carcinomas. Histopathological examination remains the gold standard for assessing lesions with potential for malignant transformation; however, the current classification of dysplasias into mild, moderate and severe cannot accurately identify which case will undergo a malignant transformation (3). There has long been a consensus according to which premalignant lesions with epithelial dysplasia more often turn into malignant lesions. Nonetheless, it has been shown that not all malignant dysplasias progress to malignancy; some of them even regress over time.

More recent studies have focused on the discovery of objective molecular markers that can identify lesions with an increased risk of malignant transformation, ideally before the occurrence of corresponding clinical and pathological changes. 


\section{Molecules associated with the phases of the cell cycle and apoptosis}

The most important feature in malignant tumors is the uncontrolled cell proliferation and the disruption to the mechanisms of induction of apoptosis (4). p53, Ki-67, p21, nuclear cell proliferation antigen (PCNA) and microsomal support protein 2 (MCM2) are some of the most studied markers of cell proliferation in oral lesions with the potential of malignant transformation (5). In addition to these, recent research indicates the relevance of the expression of D1, p16INK4 and $\mathrm{Rb}$ protein $(\mathrm{pRb})$ in the malignant transformation of these lesions (6,7). Among the above-mentioned markers, $\mathrm{Ki}-67$ is one of the most used to highlight changes that cause uncontrolled cell proliferation (8).

In the case of oral epithelial dysplasia, a correlation between the level of nuclear expression of Ki-67 and the severity of the dysplasia has been observed. Compared to Ki-67, MCM2 expression has been identified throughout the cell cycle, including in cells leaving the G0 phase (9).

PCNA is another molecule considered to be a potential biomarker, a non-histone nuclear antigen, and a marker that facilitates the estimation of the cell proliferation rate. PCNA overexpression is a marker of dysplastic epithelium and indicates a disruption of cell proliferation mechanisms in lesions with potential for malignant transformation (10). Cyclin D1 controls the transition between the G1 and the S phase of the cell cycle, and its overexpression is associated with an increase in local invasion, lymph node metastases, and, thus, a more advanced stage in the evolution of squamous cell carcinoma $(10,11)$. Rousseau et al analyzed the expression of cyclin D1 in epithelial dysplasias and squamous cell carcinomas and observed an overexpression of this protein in both cases (12).

P53 (TP53) plays an essential role in maintaining cellular homeostasis; mutations at this level are often associated with alcohol and tobacco use $(13,14)$. Numerous studies show a positive correlation between p53 expression and tumor progression, although there are a number of studies showing that the overexpression of this protein is conditioned by the location of the lesions, being more common in areas with high photo exposure. The expression of p53 protein is absent in squamous cell carcinomas, present in patients undergoing immunosuppressive treatment after organ transplantation, concluding that the expression of this protein is also regulated by the immune system. In premalignant oral lesions, overexpression of p53 is usually correlated with the degree of epithelial dysplasia, indicating an increased risk of malignant transformation (15-18). Many research teams have concluded that in the case of premalignant oral lesions, the level of p53 expression correlates directly with the risk of developing squamous cell carcinoma, even after a long time when the evolution of these lesions was monitored.

The p16 protein (also known as MTS1; multiple tumor suppressor 1) acts as a tumor suppressor, and p21, from the same family of tumor suppressors, form a complex with cyclin-dependent kinase (CDK) and proliferating nuclear cell antigen (PCNA). p16 is involved in cell proliferation, differentiation and apoptosis $(19,20)$. Studies have shown that the p16 protein controls the cell cycle phases within a mechanism independent of p53 protein expression. The results of research conducted in recent years that have evaluated p16 expression in OSCC cases developed through the malignant transformation of precursor lesions, indicate the existence of mutations in the gene encoding this protein in approximately $24 \%$ of cases. Compared to p53 expression in patients receiving post-transplant immunosuppressive therapy, overexpression of p16 was identified in both premalignant lesions and malignancies. Some studies suggest that the methylated form of p16 may be considered a marker of malignant transformation, found in both premalignant lesions and their adjacent epithelium. Recent studies consider that p16 overexpression, in addition to being a marker of malignant transformation, may also indicate an association with an infectious etiology induced by human papillomavirus (HPV). Regarding p21, its overexpression correlates with p53 overexpression, indicating an increased risk of lymph node metastasis.

Another protein that plays an important role in the normal function of the cell cycle control clock and cell differentiation is $\mathrm{pRb}$. A disruption of its expression is associated with uncontrolled cell growth and carcinogenesis (21). To this extent, the studies of de Oliveira et al (22) showed an overexpression of this protein in OSCC compared to oral premalignant lesions.

Survivin, a protein belonging to the apoptosis inhibitor family is another molecule studied as a predictive marker of malignant transformation, also involved in oral tumorigenesis $(23,24)$. Lo Muzio et al (25) identified an overexpression of survivin in $94 \%$ of the lesions undergoing malignant transformation, compared to only $30 \%$ of those without such transformation. A meta-analysis by Xie et al suggests that survivin may be used as a prognostic marker for OSCC (26).

\section{Biomarkers of angiogenesis}

Microvascular density (MVD) represents a parameter for quantifying angiogenetic patterns. An increased level of MVD is associated with the altered expression of endothelial growth factor A (VEGF-A), known for its regulatory effects on angiogenesis (27). Several retrospective studies have shown that VEGF-A levels increase significantly from normal epithelium to dysplasia and subsequently to OSCC, although an exact correlation with the severity of dysplasia has not been established. These changes were most common in oral plan lichen, while other studies did not identify significant differences from normal epithelium in its expression in minor dysplasias (28). These aspects suggest that VEGF-A expression increases in the advanced stages of tumorigenesis. In using VEGF as a biomarker, the expression of this molecule also varies; the location of the oral lesion must be taken into account. Studies have shown that serum VEGF-A expression correlates with tissue level in oral lesions with potential for malignant transformation and in organized malignant tumors, while VEGF-A receptor expression (VEGFR2) does not appear to significantly change in the case of dysplasia or even OSCC (27-30).

MDV can be quantified using the immunohistochemical evaluation of CD105 expression, a molecule used to identify the neoformation of blood vessels, with a much higher specificity compared to CD34 and CD31, given that it has an intensely positive immunoreactivity (IR) compared to weakly 
positive or even negative IR in pre-existing blood vessels. The immunohistochemical evaluation of CD105 expression indicates a significant increase in the cases of dysplasia of varying degrees compared to normal oral mucosa (31).

\section{Metalloproteinases}

Tumor invasion and progression are accompanied by extracellular matrix degradation. Matrix metalloproteinases (MMPs) are a family of zinc-dependent endopeptidases capable of degrading extracellular matrix components. In addition to their role in invasion and metastasis $(32,33)$, MMPs are involved in oncogenic tumor signaling, and their involvement in carcinogenesis and potential invasive of tumor cells has been highlighted since 2015 by Kivisaari and Kahari's studies (34). Thus, in the case of moderate and severe dysplastic lesions that present a major risk of malignant transformation, increased expression levels of MMP-1, MMP-2 and MMP-9 were highlighted and were associated with a poor prognosis. MMP-2 is absent in the cells of the normal oral mucosa, and its expression correlates with the degree of dysplasia, while in the case of OSCC its expression, as well as that of MMP-1 and MMP-9, is much reduced.

In the case of actinic keratoses and leukoplakia with moderate and severe degree of dysplasia, the results of studies by Olinici et al (35) indicate an increased expression of MMP-2, suggesting the presence of inflammatory mechanisms and the involvement of this metalloproteinase in initiating the carcinogenesis process. In patients with oral lichen planus, the same study highlights elevated levels of MMP-2, indicating the presence of systemic inflammation.

Numerous studies have highlighted the role of MMP-9 in the development of OSCC, including its use as a reserved prognostic marker, and it is generally associated with regional lymphadenopathy and/or distant metastases $(32,33,36)$. Numerous studies stipulate that the salivary, serum and tissue levels of MMP-9 are higher in lesions with potential for malignant transformation compared to control groups. However, the value of biomarkers using these molecules in malignant transformation, in the case of oral lesions, is still controversial and requires extensive studies in patient groups (37-39).

\section{Molecules associated with cell adhesion}

Numerous studies have shown that there is an association between the low expression of molecules associated with cell adhesion, decreased differentiation and the appearance of a 'mesenchymal' phenotype that facilitates invasion $(40,41)$. Transmembrane glycoproteins called cadherins are a family of $\mathrm{Ca}^{2+}$-dependent transmembrane proteins, which play an essential role in maintaining tissue integrity, because they are basic components of the structure in the intercellular coupling areas (42-45). During malignant transformation, epithelial cells show a number of morphological and molecular changes that lead, among other things, to increased migratory/invasive capacity (46-50). One of these changes is the disorganization of the structure of adhesive tapes and desmosomes, and, from a molecular point of view, it is characterized by the absence of cadherin E expression $(20,51,52)$. Cadherin $E$ is a transmembrane glycoprotein that forms a complex in membranes with $\beta$-catenin and $\alpha$-catenin. Studies have shown that the expression of cadherin $\mathrm{E}$ is reduced at the same time as that of catenins in the case of malignant transformation, suggesting their role in the malignant transformation of these lesions. It is also considered that cadherin E functions as a tumor suppressor in regards to the ability of tumor cells to metastasize; its absence from epithelial cells causing disorganization of desmosomes, followed by local and/or distant invasiveness and a worse prognosis $(53,54)$.

In premalignant oral lesions, existing studies indicate a reduction in the membrane expression of cadherin $\mathrm{E}$ and overexpression at the cytoplasmic level, aspects that correlate inversely with the degree of dysplasia (55). A number of leukoplakias may show a pattern of cadherin expression similar to that of the normal mucosa, indicating a reduced risk of malignant transformation. Desmoplakin and placophyllin-1 are considered markers for cell coupling areas and show a weakly positive and diffuse expression in dysplastic epithelial cells. In the case of OSCC, the desmoplakin expression is absent, and for placophyllin-1 in most cases, only a weak, diffuse expression was found in the cytoplasm of tumor cells.

Ezrin is a protein present at the apical pole of the epithelial cell membrane and it is one of the molecules considered a marker of the malignant transformation mechanisms, identified in recent years. This molecule makes the connection between the membrane and actin $\mathrm{F}$ at the level of the membrane cytoskeleton, being able to activate GTPases to induce a remodeling at the membrane level. Thus, it has an important role in the processes of cell proliferation, differentiation and migration. The expression of this molecule correlates positively with the expression of $\mathrm{Ki}-67$, in the case of the evolution of premalignant oral lesions. In normal oral mucosal cells, ezrin shows positive IR at the membrane level, while in the case of leukoplakia, an intensely positive intracytoplasmic and weakly positive expression was found at the membrane level. In the erosive lichen planus, a punctiform cytoplasmic immunopositivity sometimes perinuclear-concentrated was observed, according to a study published by Olinici et al (35). The results of other studies also highlight an overexpression of ezrin with predominantly cytoplasmic localization in the case of OSCC, compared to premalignant lesions $(56,57)$. Ezrin is currently considered a possible target for antitumor therapies aimed at reducing the ability of tumor cells to metastasize $(58,59)$.

\section{Conclusions}

Given the poor prognosis of OSCC, preventing the appearance of malignant tumors by identifying and treating premalignant lesions with an increased risk of transformation would be ideal. The limitations including the fact that we cannot specify with certainty which premalignant lesions will evolve towards a malignant tumor, make establishing clear protocols for managing these lesions difficult, resulting in the excessive treatment of some lesions, while others are improperly treated, or not at all. The difficult management of these premalignant lesions also indicates that the chain of molecular events leading to oral carcinogenesis has not yet been fully elucidated. 
Unfortunately, there are still no clear guidelines for screening and early detection of oral cancers, as screening for precursor lesions is not properly conducted. Identifying high-risk populations, as well as validating methods for screening oral lesions with the potential for malignant transformation, is an essential step in the therapy and prognosis of oral cancers.

Currently, the diagnosis is based on the clinical appearance and histopathological examination, considered the 'gold standard', but fully dependent on the ability of the clinician and pathologist to observe a number of changes. The use of specific biomarkers may lead to the early detection of these lesions and prevent the development of OSCC.

A targeted therapeutic approach, taking into account changes at the molecular level, could prevent the clinical and histopathological evolution of lesions with malignant transformation potential and offer the possibility to opt for a certain type of therapy, depending on the molecular profile and the risk of transformation of each lesion, which would significantly reduce the number of oral cancers.

Although some of the markers presented have a theoretical potential only to be used to monitor the risk of malignant transformation of oral lesions, further research in this direction may lead to the development of a panel of biomarkers functional in current practice.

\section{Acknowledgements}

Professional editing, linguistic and technical assistance was performed by Irina Radu.

\section{Funding}

No funding was received.

\section{Availability of data and materials}

All data generated or analyzed during this study are included in this published article.

\section{Authors' contributions}

$\mathrm{OMCH}, \mathrm{AEB}, \mathrm{DTO}, \mathrm{PO}$ and LS conducted the literature research and results of the literature research filtering. $\mathrm{OMCH}, \mathrm{AEB}, \mathrm{DTO}$, VBG and PMT performed the critical analysis of the studies and evaluation of the quality of the identified studies. $\mathrm{OMCH}, \mathrm{AEB}$, DTO, LGS and ECC conducted evaluation of the evidence level, interpretive analysis of findings across multiple studies and article writing. All authors read and approved the final manuscript.

\section{Ethics approval and consent to participate}

Not applicable.

\section{Patient consent for publication}

Not applicable.

\section{Competing interests}

The authors declare that they have no competing interests.

\section{References}

1. Siegel RL, Miller KD and Jemal A: Cancer Statistics 2020. CA Cancer J Clin 70: 7-30, 2020.

2. Ferlay J, Soerjomataram I, Dikshit R, Eser S, Mathers C, Rebelo M, Parkin DM, Forman D and Bray F: Cancer incidence and mortality worldwide: Sources methods and major patterns in GLOBOCAN 2012. Int J Cancer 136: E359-E386, 2015.

3. Warnakulasuriya S: Global epidemiology of oral and oropharyngeal cancer. Oral Oncol 45: 309-316, 2009.

4. Hanahan D and Weinberg RA: Hallmarks of cancer: The next generation. Cell 144: 646-674, 2011.

5. Lingen MW, Pinto A, Mendes RA, Franchini R, Czerninski R, Tilakaratne WM, Partridge M, Peterson DE and Woo SB: Genetics/epigenetics of oral premalignancy: Current status and future research. Oral Dis 17 (Suppl 1): S7-S22, 2011.

6. Nasser W, Flechtenmacher C, Holzinger D, Hofele C and Bosch XF: Aberrant expression of p53, p16INK4a and Ki-67 as basic biomarker for malignant progression of oral leukoplakias. J Oral Pathol Med 40: 629-635, 2011.

7. Solomon I, Voiculescu VM, Caruntu C, Lupu M, Popa A, Ilie MA, Albulescu R, Caruntu A, Tanase C, Constantin C, et al: Neuroendocrine factors and head and neck squamous cell carcinoma: An affair to remember. Dis Markers 2018: 9787831, 2018.

8. Verheijen R, Kuijpers HJ, Schlingemann RO, Boehmer AL, van Driel R, Brakenhoff GJ and Ramaekers FC: Ki-67 detects a nuclear matrix-associated proliferation-related antigen. I. Intracellular localization during interphase. J Cell Sci 92: 123-130, 1989.

9. Torres-Rendon A, Roy S, Craig GT and Speight PM: Expression of $\mathrm{Mcm} 2$, geminin and $\mathrm{Ki67}$ in normal oral mucosa, oral epithelial dysplasias and their corresponding squamous-cell carcinomas. Br J Cancer 100: 1128-1134, 2009.

10. Mallick S, Agarwal J, Kannan S, Pawar S, Kane S and Teni T: PCNA and anti-apoptotic Mcl-1 proteins predict disease-free survival in oral cancer patients treated with definitive radiotherapy. Oral Oncol 46: 688-693, 2010.

11. Dionne KR, Warnakulasuriya S, Zain RB and Cheong SC: Potentially malignant disorders of the oral cavity: Current practice and future directions in the clinic and laboratory. Int J Cancer 136: 503-515, 2015.

12. Rousseau A, Lim MS, Lin Z and Jordan RC: Frequent cyclin D1 gene amplification and protein overexpression in oral epithelial dysplasias. Oral Oncol 37: 268-275, 2001.

13. Boda D, Docea AO, Calina D, Ilie MA, Caruntu C, Zurac S, Neagu M, Constantin C, Branisteanu DE, Voiculescu V, et al: Human papilloma virus: Apprehending the link with carcinogenesis and unveiling new research avenues (Review). Int J Oncol 52: 637-655, 2018.

14. Perez-Ordonez B, Beauchemin M and Jordan RC: Molecular biology of squamous cell carcinoma of the head and neck. J Clin Pathol 59: 445-453, 2006.

15. Öhman J, Mowjood R, Larsson L, Kovacs A, Magnusson B, Kjeller G, Jontell M and Hasseus B: Presence of CD3-Positive T-cells in oral premalignant leukoplakia indicates prevention of cancer transformation. Anticancer Res 35: 311-317, 2015.

16. Chang KW, Lin SC, Kwan PC and Wong YK: Association of aberrant p53 and p21 (WAF1) immunoreactivity with the outcome of oral verrucous leukoplakia in Taiwan. J Oral Pathol Med 29: 56-62, 2000.

17. Vieira RA, Minicucci EM, Marques ME and Marques SA: Actinic cheilitis and squamous cell carcinoma of the lip: Clinical, histopathological and immunogenetic aspects. An Bras Dermatol 87: 105-114, 2012.

18. Calenic B, Greabu M, Caruntu C, Nicolescu MI, Moraru L, Surdu-Bob CC, Badulescu M, Anghel A, Logofatu C and Boda D: Oral keratinocyte stem cells behavior on diamond like carbon films. Rom Biotechnol Lett 21: 11914-11922, 2016.

19. Lu S, Tiekso J, Hietanen S, Syrjänen K, Havu VK and Syrjänen S: Expression of cell-cycle proteins p53, p21 (WAF-1), PCNA and Ki-67 in Benign, premalignant and malignant skin lesions with implicated HPV involvement. Acta Derm Venereol 79: 268-273, 1999.

20. Presland RB and Jurevic RJ: Making sense of the epithelial barrier: What molecular biology and genetics tell us about the functions of oral mucosal and epidermal tissues. J Dent Educ 66: 564-574, 2002.

21. Uchida C: Roles of pRB in the regulation of nucleosome and chromatin structures. Biomed Res Int 2016: 5959721, 2016. 
22. de Oliveira GM, Ramalho LM, Gaiao L, Pozza DH and de Mello RA: Retinoblastoma and p53 protein expression in pre-malignant oral lesions and oral squamous cell carcinoma. Molecular Med Rep 6: 163-166, 2012.

23. $\mathrm{Li} \mathrm{F}$ : Role of survivin and its splice variants in tumorigenesis. $\mathrm{Br}$ J Cancer 92: 212-216, 2005

24. Lupu M, Caruntu A, Caruntu C, Boda D, Moraru L, Voiculescu V and Bastian A: Non-invasive imaging of actinic cheilitis and squamous cell carcinoma of the lip. Mol Clin Oncol 8: 640-646, 2018.

25. Lo Muzio L, Pannone G, Leonardi R, Staibano S, Mignogna MD, de Rosa G, Kudo Y, Takata T and Altieri DC: Survivin, a potential early predictor of tumor progression in the oral mucosa. J Dent Res 82: 923-928, 2003.

26. Xie S, Xu H, Shan X, Liu B, Wang K and CaiZ: Clinicopathological and prognostic significance of survivin expression in patients with oral squamous cell carcinoma: Evidence from a meta-analysis. PLoS One 10: 0116517, 2015.

27. Thiem DGE, Schneider S, Venkatraman NT, Kumar VV, Brieger J, Frerich B and Kämmerer PW: Semiquantifiable angiogenesis parameters in association with the malignant transformation of oral leukoplakia. J Oral Pathol Med 46: 710-716, 2017.

28. Johnstone S and Logan RM: Expression of vascular endothelial growth factor (VEGF) in normal oral mucosa, oral dysplasia and oral squamous cell carcinoma. Int J Oral Maxillofac Surg 36 263-266, 2007.

29. Boda D: Cellomics as integrative omics for cancer. Curr Proteomics 10: 237-245, 2013.

30. Michailidou EZ, Markopoulos AK and Antoniades DZ: VEGF expression from human dysplastic or malignant oral epithelium may be related to mast cell density and the subsequent angiogenetic phenomena. Int J Oral Maxillofac Surg 41: 1467-1473, 2012

31. Gadbail AR, Chaudhary MS, Sarode SC, Gawande M, Korde S, Tekade SA, Gondivkar S, Hande A and Maladhari R: Ki67, CD105, and $\alpha$-SMA expressions better relate the binary oral epithelial dysplasia grading system of World Health Organization. J Oral Pathol Med 46: 921-927, 2017.

32. Stamenkovic I: Extracellular matrix remodelling: The role of matrix metalloproteinases. J Pathol 200: 448-464, 2003.

33. Kosunen A, Pirinen R, Ropponen K, Pukkila M, Kellokoski J, Virtaniemi J, Sironen R, Juhola M, Kumpulainen E, Johansson R, et al: CD44 expression and its relationship with MMP-9, clinicopathological factors and survival in oral squamous cell carcinoma. Oral Oncol 43: 51-59, 2007.

34. Kivisaari A and Kähäri VM: Squamous cell carcinoma of the skin: Emerging need for novel biomarkers. World J Clin Oncol 4 85-90, 2013.

35. Olinici D, Gheucă-Solovăstru L, Stoica L, Bădescu L, Onofrei P, Botez EA and Cotrutz CE: The molecular mosaic of the premalignant cutaneous lesions-Review. Rom J Morphol Embryol 57: 353-359, 2016

36. Katayama A, Bandoh N, Kishibe K, Takahara M, Ogino T, Nonaka S and Harabuchi Y: Expressions of matrix metalloproteinases in early-stage oral squamous cell carcinoma as predictive indicators for tumor metastases and prognosis. Clin Cancer Res 10: 634-640, 2004

37. Chang PY, Kuo YB, Wu TL, Liao CT, Sun YC, Yen TC and Chan EC: Association and prognostic value of serum inflammation markers in patients with leukoplakia and oral cavity cancer. Clin Chem Lab Med 51: 1291-1300, 2013.

38. Saxena G, Koli K, de la Garza J and Ogbureke KU: Matrix metalloproteinase 20-dentin sialophosphoprotein interaction in oral cancer. J Dent Res 94: 584-593, 2015.

39. Bajracharya D, Shrestha B, Kamath A, Menon A and Radhakrishnan R: Immunohistochemical correlation of matrix metalloproteinase-2 and tissue inhibitors of metalloproteinase-2 in tobacco associated epithelial dysplasia. Dis Markers 2014: 197813,2014

40. von Zeidler SV, de Souza Botelho T, Mendonça EF and Batista AC: E-cadherin as a potential biomarker of malignant transformation in oral leukoplakia: A retrospective cohort study. BMC Cancer 14: 972, 2014.

41. Williams HK, Sanders DS, Jankowski JA, Landini G and Brown AM: Expression of cadherins and catenins in oral epithelial dysplasia and squamous cell carcinoma. J Oral Pathol Med 27: 308-317, 1998

42. Papadimitrakopoulou VA, William WN Jr, Dannenberg AJ, Lippman SM, Lee JJ, Ondrey FG, Peterson DE, Feng L, Atwell A, El-Naggar AK, et al: Pilot randomized phase II study of celecoxib in oral premalignant lesions. Clin Cancer Res 14 2095-2101, 2008.
43. Saba NF, Haigentz M Jr, Vermorken JB, Strojan P, Bossi P, Rinaldo A, Takes RP and Ferlito A: Prevention of head and neck squamous cell carcinoma: Removing the 'chemo' from 'chemoprevention'. Oral Oncol 51: 112-118, 2015.

44. Jyothi Meka N, Ugrappa S, Velpula N, Kumar S, Naik Maloth K, Kodangal S, Ch L and Goyal S: Quantitative immunoexpression of EGFR in oral potentially malignant disorders: Oral leukoplakia and oral submucous fibrosis. J Dent Res Dent Clin Dent Prospects 9: 166-174, 2015.

45. Ribeiro DC, Gleber-Netto FO, Sousa SF, Bernardes VD, Guimaraes-Abreu MH and Aguiar MC: Immunohistochemical expression of EGFR in oral leukoplakia: Association with clinicopathological features and cellular proliferation. Med Oral Patol Oral Cir Bucal 17: e739-e744, 2012.

46. Taoudi Benchekroun M, Saintigny P, Thomas SM, El-Naggar AK, Papadimitrakopoulou V, Ren H, Lang W, Fan YH, Huang J, Feng L, et al: Epidermal growth factor receptor expression and gene copy number in the risk of oral cancer. Cancer Prev Res (Phila) 3: 800-809, 2010.

47. Poh CF, Zhu Y, Chen E, Berean KW, Wu L, Zhang L and Rosin MP: Unique FISH patterns associated with cancer progression of oral dysplasia. J Dental Res 91: 52-57, 2012.

48. Saba NF, Hurwitz SJ, Kono SA, Yang CS, Zhao Y, Chen Z, Sica G, Müller S, Moreno-Williams R, Lewis M, et al: Chemoprevention of head and neck cancer with celecoxib and erlotinib: Results of a phase ib and pharmacokinetic study. Cancer Prev Res (Phila) 7: 283-291, 2014.

49. Amornphimoltham P, Patel V, Sodhi A, Nikitakis NG, Sauk JJ, Sausville EA, Molinolo AA and Gutkind JS: Mammalian target of rapamycin, a molecular target in squamous cell carcinomas of the head and neck. Cancer Res 65: 9953-9961, 2005.

50. Martins F, de Sousa SC, Dos Santos E, Woo SB and Gallottini M: PI3KAKT-mTOR pathway proteins are differently expressed in oral carcinogenesis. J Oral Pathol Med 45: 746-752, 2016.

51. Navarro P, Gómez M, Pizarro A, Gamallo C, Quintanilla M and Cano A: A role for the E-Cadherin cell-cell adhesion molecule during tumor progression of mouse epidermal carcinogenesis. J Cell Biol 115: 517-533, 1991

52. Brennan D, Hu Y, Joubeh S, Choi YW, Whitaker-Menezes D, O'Brien T, Uitto J, Rodeck U and Mahoney MG: Suprabasal Dsg2 expression in transgenic mouse skin confers a hyperproliferative and apoptosis-resistant phenotype to keratinocytes. J Cell Sci 120 (Pt 5): 758-771, 2007

53. Alt-Holland A, Zhang W, Margulis A and Garlick JA Microenvironmental control of premalignant disease: The role of intercellular adhesion in the progression of squamous cell carcinoma. Semin Cancer Biol 15: 84-96, 2005.

54. Chidgey $\mathrm{M}$ and Dawson C: Desmosomes: A role in cancer? $\mathrm{Br}$ J Cancer 96: 1783-1787, 2007.

55. Vilen ST, Salo T, Sorsa T and Nyberg P: Fluctuating roles of matrix metalloproteinase 9 in oral squamous cell carcinoma. ScientificWorldJournal 2013: 920595, 2013.

56. Bagheri M, Eghtedari M, Bagheri M, Geramizadeh B and Talebnejad M: Expression of maspin and ezrin proteins in periocular basal cell carcinoma. Dermatol Res Pract 2014: 596564 2014.

57. Gamei MM, el Naby NMA, El-Ashmawy AA and Shareef MM: Prognostic value of ezrin expression in common epithelial tumors: An immunohistochemical study. J Microsc Ultrastructure 2: 67-76, 2014.

58. Kaur J, Sawhney M, DattaGupta S, Shukla NK, Srivastava A, Walfish PG and Ralhan R: Clinical significance of altered expression of $\beta$-catenin and E-cadherin in oral dysplasia and cancer: Potential link with ALCAM expression. PLoS One 8: e67361, 2013

59. Suciu M, Morariu SH, Ormenişan A, Grigoraş RI, Bostan RH, Mocanu S, Vartolomei MD and Cotoi OS: Oral squamous cell carcinoma of the maxilla, a second malignancy after a right ethmoido-maxillary chondrosarcoma. Rom J Morphol Embryol 55 (Suppl 3): S1247-S1251, 2014.

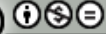

This work is licensed under a Creative Commons Attribution-NonCommercial-NoDerivatives 4.0 International (CC BY-NC-ND 4.0) License. 